\title{
Cautious epoprostenol therapy is a safe bridge to lung transplantation in pulmonary veno-occlusive disease
}

\author{
D. Montani*, X. Jaïs*, L.C. Price*\#, L. Achouh*, B. Degano*, O. Mercier", S. Mussot", \\ E. Fadel ${ }^{\star}$, P. Dartevelle ${ }^{\star}$, O. Sitbon*, G. Simonneau* and M. Humbert*
}

ABSTRACT: Pulmonary veno-occlusive disease (PVOD) carries a poor prognosis and lung transplantation is the only curative treatment. In PVOD, epoprostenol therapy is controversial, as this condition may be refractory to specific therapy with an increased risk of pulmonary oedema.

We retrospectively reviewed clinical, functional and haemodynamic data of 12 patients with PVOD (10 with histological confirmation) treated with continuous intravenous epoprostenol and priority listed for lung transplantation after January 1, 2003.

All PVOD patients had severe clinical, functional and haemodynamic impairment at presentation. Epoprostenol was used at low dose ranges with slow dose increases and high dose diuretics. Only one patient developed mild reversible pulmonary oedema. After 3-4 months, improvements were seen in the New York Heart Association functional class (class IV to III in seven patients), cardiac index $\left(1.99 \pm 0.68\right.$ to $\left.2.94 \pm 0.89 \mathrm{~L} \cdot \mathrm{min}^{-1} \cdot \mathrm{m}^{-2}\right)$ and indexed pulmonary vascular resistance $\left(28.4 \pm 8.4\right.$ to $17 \pm 5.2$ Wood units $\cdot \mathrm{m}^{-2}$; all $\left.\mathrm{p}<0.01\right)$. A nonsignificant improvement in the 6-min walk distance was also observed $(+41 \mathrm{~m}, \mathrm{p}=0.11)$. Two patients died, one patient was alive on the transplantation waiting list on December 1, 2008 and nine patients were transplanted.

Cautious use of continuous intravenous epoprostenol improved clinical and haemodynamic parameters in PVOD patients at 3-4 months without commonly causing pulmonary oedema, and may be a useful bridge to urgent lung transplantation.

KEYWORDS: Epoprostenol, lung transplantation, prostacyclin, pulmonary arterial hypertension, pulmonary oedema, pulmonary veno-occlusive disease

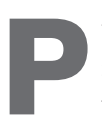
ulmonary arterial hypertension $(\mathrm{PAH})$ is a severe condition characterised by elevated pulmonary artery pressure and normal pulmonary capillary wedge pressure (Ppcw), leading to right heart failure and death [1-3] Pulmonary veno-occlusive disease (PVOD) is a subgroup of pulmonary hypertension with clinical similarities with PAH defined by specific pathological changes of the small pulmonary veins, and it represents $5-10 \%$ of histological forms of cases initially considered as idiopathic PAH [4-7]. A definitive diagnosis of PVOD has been considered to require histological examination of lung samples showing extensive and diffuse occlusion of pulmonary veins by fibrous tissue and intimal thickening involving preferentially venules and small veins in lobular septa [810]. We have recently demonstrated that a noninvasive approach can be helpful to screen for PVOD patients [6]. Following this, we have used a noninvasive approach to screen patients with a high clinical suspicion of PVOD with methods including high-resolution computed tomography (HRCT) of the chest, diffusing capacity of the lung for carbon monoxide $(D \mathrm{~L}, \mathrm{CO})$ and bronchoalveolar lavage $[6,11,12]$.

PVOD patients have a very poor prognosis and the recommended treatment is lung transplantation [4-7]. In these patients with severe pulmonary vascular disease, the waiting time for transplantation may exceed their expected survival. While specific PAH therapies such as intravenous prostacyclin have established efficacy in treatment of $\mathrm{PAH}[3,13]$, benefits of these treatments in patients with PVOD are unclear, as these patients may be refractory to $\mathrm{PAH}$-specific therapy and may even deteriorate with it. Recently, MONTANI et al. [6] reported the occurrence of pulmonary oedema with different specific PAH therapies (epoprostenol, bosentan, calcium channel-blocker) suggesting that pulmonary oedema is not due to a

\section{AFFILIATIONS}

*Université Paris-Sud, Faculté de médecine, Centre National de Référence de l'Hypertension Pulmonaire Sévère, Service de Pneumologie et Réanimation Respiratoire, AP-HP, INSERM U999, Hôpital Antoine Béclère, Clamart, and - Université Paris-Sud, UPRES EA 2705, Service de Chirurgie Thoracique, Centre Chirurgical Marie-Lannelongue, Université ParisSud, Le Plessis-Robinson, France. \#Imperial College London, National Pulmonary Hypertension Service, Hammersmith Hospital, London, UK.

\section{CORRESPONDENCE}

M. Humbert

Centre National de Référence de l'Hypertension Pulmonaire Sévère, Service de Pneumologie et Réanimation Respiratoire Hôpital Antoine Béclère

157 rue de la porte de Trivaux Clamart

F-92140

France

E-mail: marc.humbert@abc.aphp.fr

Received:

Feb 022009

Accepted after revision:

May 292009

First published online:

June 182009

European Respiratory Journa

Print ISSN 0903-1936

Online ISSN 1399-3003 
therapeutic class effect but may occur with all specific PAH therapies. In this series [6], nearly half of the PVOD patients treated with epoprostenol developed pulmonary oedema. However, continuous intravenous epoprostenol is considered to be the most potent therapy in severe $\mathrm{PAH}$, combining pulmonary vasodilatory and antiproliferative effects, and it has been shown to improve exercise capacity, haemodynamics and survival of idiopathic PAH patients [3, 14-18]. Epoprostenol has been proposed as a bridging therapy in various severe pulmonary vascular diseases including various $\mathrm{PAH}$ variants and nonoperable chronic thromboembolic pulmonary hypertension patients awaiting lung transplantation [3, 14-19]. In PVOD, isolated case reports suggested that cautious use of epoprostenol may be helpful to stabilise the condition $[4,10,20]$. With the improved identification of this rare subgroup of $\mathrm{PAH}$, we hypothesised that continuous intravenous epoprostenol, when used in a cautious manner, could improve haemodynamic and functional status of severe PVOD patients waiting for lung transplantation and may be used as a bridge to lung transplantation. The aim of the present study was to report our experience on the use of epoprostenol in PVOD patients awaiting lung transplantation.

\section{METHODS}

\section{Patients}

We retrospectively reviewed data from patients referred to the French Reference Center for Pulmonary Hypertension (Université Paris-Sud 11, Hôpital Antoine Béclère, Clamart, France) with confirmed or highly probable PVOD, treated with continuous intravenous epoprostenol and listed for lung transplantation after January 1, 2003. Two patients were reported in a previous article [6]. Diagnosis of PVOD was considered as confirmed when histological proof of venoocclusive disease (biopsy, post mortem or lungs obtained after lung transplantation) was available or when pulmonary oedema had occurred with specific PAH therapy. The diagnosis of PVOD was considered as very highly probable if patients fulfilled the characteristics we have previously described [6]: pre-capillary pulmonary hypertension confirmed by right-heart catheterisation, presence of $\geqslant 2$ radiological abnormalities on HRCT of the chest (including lymph node enlargement, centrilobular ground-glass opacities and septal lines), low DL,CO and occult alveolar haemorrhage. Pulmonary hypertension occurring in patients associated with other conditions (connective tissue diseases, human immunodeficiency virus infection, portal hypertension, congenital heart diseases and chronic respiratory diseases) were excluded from the study. All clinical characteristics at diagnosis and follow-up were stored in the Registry of the French Network of Pulmonary Hypertension. This registry was set up in agreement with French bioethics laws (French Commission Nationale de l'Informatique et des Libertés) and all patients gave their informed consent [21].

\section{Pathology}

Haematoxylin-eosin-safran staining was used to characterise pulmonary vascular abnormalities. The pathological hallmark of PVOD was defined as an extensive and diffuse obstruction of pulmonary veins and venules by intimal fibrosis, cellular proliferation and muscularisation $[8,22,23]$. When available, occult alveolar haemorrhage was assessed using the Golde score on bronchoalveolar lavage performed during bronchoscopy, and an alveolar haemorrhage was defined by a Golde score $>100$ [12]. Histological confirmation was obtained from explanted lung in nine patients $(75 \%)$ and by autopsy in one patient $(8 \%)$; one patient died without post-mortem analysis and one patient was still waiting for lung transplantation on December 1, 2008.

\section{Haemodynamic measurements}

Pre-capillary pulmonary hypertension was defined as mean pulmonary artery pressure $\left(\bar{P}_{\mathrm{pa}}\right)>25 \mathrm{mmHg}$ with a normal $P$ pcw $<15 \mathrm{mmHg}$. $\bar{P}_{\text {pa, }}$ P pcw, right atrial pressure (RAP) and mixed venous oxygen saturation $\left(\mathrm{SV}, \mathrm{O}_{2}\right)$ were recorded. Cardiac output $(\mathrm{CO})$ was measured by the standard thermodilution technique. The cardiac index $(\mathrm{CI})$ was calculated as the $\mathrm{CO}$ divided by the body surface area and systolic index as the $\mathrm{CI}$ divided by heart rate. The indexed pulmonary vascular resistance (PVRi) was calculated as $\left(\bar{P}_{\mathrm{pa}}-\mathrm{Ppcw}_{\mathrm{pc}}\right) / \mathrm{CI}$, expressed in Wood units $(\mathrm{WU}) \cdot \mathrm{m}^{-2}$. Baseline haemodynamic data and response to short-term vasodilator nitric oxide (NO) were performed for all subjects. An NO challenge (10 ppm for 5$10 \mathrm{~min}$ ) was used and a positive acute response was defined as a decrease in $\bar{P}_{\text {pa }}$ of $>10 \mathrm{mmHg}$ compared with the baseline $\bar{P}_{\text {pa }}$ to a $\bar{P}_{\text {pa }}<40 \mathrm{mmHg}$ and a normal or increased CO, as previously described [24].

\section{Clinical and functional assessment}

Routine evaluation at baseline included medical history and physical examination. Age at diagnosis, smoking habits, and clinical status assessed by modified New York Heart Association (NYHA) functional class [2, 3] were recorded at diagnosis. A non-encouraged 6-min walk test according to the American Thoracic Society recommendations [25] was performed. The 6-min walk distance (6-MWD) and the lowest pulse arterial oxygen saturation (minimal $S \mathrm{p}, \mathrm{O}_{2}$ ) were both recorded [26, 27]. Arterial blood gases and lung function tests were performed: partial pressure of arterial oxygen $\left(\mathrm{Pa}_{\mathrm{a}} \mathrm{O}_{2}\right)$ and DL,CO were recorded.

\section{Epoprostenol therapy}

Continuous intravenous epoprostenol was initiated in PVOD patients eligible for lung transplantation in NYHA functional class III or IV with severely impaired haemodynamics. All patients received continuous intravenous epoprostenol initiated during hospitalisation. At the time of epoprostenol initiation, nonspecific therapy including warfarin, diuretics, dobutamine and oxygen if needed and associated specific $\mathrm{PAH}$ therapies were recorded. The occurrence of pulmonary oedema and the need to increase diuretics after initiation of continuous epoprostenol were reported. Management of epoprostenol therapy was also recorded, including the time between diagnosis and initiation, the maximum dose, the time to reach the maximal dose and the length of epoprostenol therapy. We recorded data regarding NYHA functional class, haemodynamics, pulmonary function tests and 6-MWD from evaluation at 3-4 months and at 9-12 months after initiation of epoprostenol.

\section{Lung transplantation}

All the patients were listed for lung transplantation at the time of epoprostenol initiation. According to current national 
guidelines for pulmonary or cardiopulmonary transplantation, PVOD patients could be listed for an urgent priority transplantation procedure if they were at high risk of shortterm mortality, as defined by persistent clinical and haemodynamic instability requiring continuous vasoactive drug infusion (dobutamine and norepinephrine) in the intensive care unit. The time between listing for lung transplantation and transplantation or death, the type of lung transplantation (heart and lungs or double lungs) and mortality at day 28 posttransplantation were recorded.

\section{Statistical analysis}

Statistical analysis was performed using Stat view version 5.0 (Abacus Concepts Inc., Berkley, CA, USA). Data are presented as mean \pm SD unless stated otherwise. Comparisons of haemodynamic data between baseline evaluation and 3-4 months later were assessed by paired t-tests or by nonparametric tests if needed. Survival analyses were calculated using the KaplanMeier method. For patients who were transplanted before the haemodynamic evaluation at 3-4 months, we used the last evaluation of NYHA functional class and 6-MWD, and the haemodynamic characteristics on the day of lung transplantation. For the only patient who died before haemodynamic evaluation, we used the worse value of 6-MWD and haemodynamic characteristics of the cohort in the statistical analysis.

\section{RESULTS}

\section{Baseline characteristics}

Between January 1, 2003 and December 1, 2008, 12 PVOD patients treated with continuous intravenous epoprostenol and listed for lung transplantation were identified. Eleven patients $(91.7 \%)$ had a confirmed diagnosis of PVOD: 10 patients had histologically confirmed PVOD on explanted lungs and one patient with characteristics of PVOD (three radiological abnormalities, DL,CO of $43 \%$ ) developed pulmonary oedema with calcium channel blocker therapy. The last patient was waiting for lung transplantation on December 1, 2008 and had highly probable PVOD with pre-capillary pulmonary hypertension associated with two radiological abnormalities (centrilobular ground-glass opacities and septal lines), DL,CO of $25 \%$ and an occult alveolar haemorrhage on bronchoalveolar lavage.

Demographic, clinical, functional and haemodynamic characteristics at diagnosis of the PVOD patients are presented in table 1. As previously described [4-7], there was no female predominance and tobacco exposure was common in this patient population. One patient had a family history of PVOD (a sister with histologically confirmed PVOD). This patient and seven other PVOD patients without family history were screened for the BMPR2 mutation and, interestingly, a BMPR2 mutation was found in a patient without a known family history of PAH or PVOD. At the time of diagnosis, most of the patients were in NYHA functional class III (class II, $n=1$; class III, $n=8$ and class IV, n=3) with severe haemodynamic impairment (high PVRi, low $\mathrm{CI}$ and $\mathrm{SV}, \mathrm{O}_{2}$ and normal $P$ pcw; table 1). PVOD patients typically had low resting $\mathrm{Pa}_{\mathrm{a}} \mathrm{O}_{2}$, marked oxygen desaturation during 6-MWD, very low $D \mathrm{~L}, \mathrm{CO}$ and possible occult alveolar haemorrhage $(n=3,33.3 \%)[4-7,12]$. Furthermore, at least two classical radiological abnormalities, including lymph node enlargement, centrilobular ground-glass opacities and septal lines, were found in all patients. The patient who responded favourably to acute vasodilator testing (NO) was the only patient in functional class II at the time of diagnosis. This patient developed pulmonary oedema and clinical deterioration with calcium channel blocker therapy prior to cautious initiation of continuous intravenous epoprostenol. Despite the fact that only one patient was an acute NO responder according to the current definition [24], an element of acute vasoreactivity to $\mathrm{NO}$ was relatively frequent with a mean change of $\bar{P}_{\text {pa during } \mathrm{NO} \text { testing }}$ of $6 \pm 4 \mathrm{mmHg}(\mathrm{p}<0.001$ and compared with baseline).

\section{Epoprostenol therapy}

NYHA functional class, 6-MWD and haemodynamic characteristics of PVOD patients at the time of initiation of epoprostenol are presented in table 2. At this time, all PVOD patients were in

\begin{tabular}{|c|c|c|}
\hline \multirow[t]{2}{*}{ TABLE 1} & \multicolumn{2}{|c|}{$\begin{array}{l}\text { Characteristics of pulmonary veno-occlusive } \\
\text { disease patients at diagnosis of pre-capillary } \\
\text { pulmonary hypertension }\end{array}$} \\
\hline & & At diagnosis \\
\hline \multicolumn{2}{|c|}{ Sex male/female $n$} & $7 / 5$ \\
\hline \multicolumn{2}{|c|}{ Age at diagnosis yrs } & $41 \pm 12$ \\
\hline \multicolumn{2}{|c|}{ Tobacco exposure pack-yrs } & $16 \pm 17.3$ \\
\hline \multicolumn{3}{|c|}{ NYHA class at diagnosis } \\
\hline \multicolumn{2}{|c|}{ Class ॥ } & $1(8.3)$ \\
\hline \multicolumn{2}{|l|}{ Class III } & $8(66.7)$ \\
\hline \multicolumn{2}{|l|}{ Class IV } & $3(25)$ \\
\hline \multicolumn{3}{|c|}{ 6-min walk test } \\
\hline \multicolumn{2}{|c|}{ Distance m } & $353 \pm 103$ \\
\hline \multicolumn{2}{|c|}{ Nadir $\mathrm{Sp}, \mathrm{O}_{2} \%$} & $83 \pm 6$ \\
\hline \multicolumn{2}{|c|}{$\mathrm{Pa}, \mathrm{O}_{2} \mathrm{mmHg}$} & $66 \pm 8$ \\
\hline \multicolumn{2}{|c|}{$\mathrm{Pa}, \mathrm{CO}_{2} \mathrm{mmHg}$} & $29 \pm 4$ \\
\hline \multicolumn{2}{|c|}{ DL,co \% pred } & $34 \pm 14$ \\
\hline \multicolumn{2}{|c|}{$\bar{P}_{\text {pa }} \mathrm{mmHg}$} & $56 \pm 10$ \\
\hline \multicolumn{2}{|l|}{ RAP mmHg } & $8 \pm 6$ \\
\hline \multicolumn{2}{|l|}{ Ppcw mmHg } & $7 \pm 3$ \\
\hline \multicolumn{2}{|c|}{ CI L $\cdot \min ^{-1} \cdot \mathrm{m}^{-2}$} & $2.40 \pm 0.72$ \\
\hline \multicolumn{2}{|c|}{$\mathrm{SI} \mathrm{mL} \cdot \mathrm{m}^{-2}$} & $26 \pm 5$ \\
\hline \multicolumn{2}{|l|}{ PVRi WU $\cdot \mathrm{m}^{-2}$} & $23.3 \pm 10.6$ \\
\hline \multicolumn{2}{|l|}{$\mathrm{Sv}, \mathrm{O}_{2} \%$} & $61 \pm 12$ \\
\hline \multicolumn{2}{|c|}{ Acute NO responders } & $1(8.3)$ \\
\hline \multicolumn{2}{|c|}{$\Delta \bar{P}_{\text {pa }}$ with NO \% } & $10 \pm 7$ \\
\hline \multicolumn{2}{|c|}{$\begin{array}{l}\text { patients with } \geqslant 2 \text { radiological } \\
\text { abnormalities }{ }^{\#} n\end{array}$} & $12(100)$ \\
\hline \multicolumn{2}{|c|}{ Occult alveolar haemorrhage } & 3/9 (33.3) \\
\hline \multicolumn{3}{|c|}{$\begin{array}{l}\text { Data are preented as mean } \pm \mathrm{SD} \text { or } \mathrm{n}(\%) \text {, unless otherwise indicated. } \mathrm{NYHA} \text { : } \\
\text { New York Heart Association; } \mathrm{Sp}_{\mathrm{O}} \mathrm{O}_{2} \text { : pulse arterial oxygen saturation; } \mathrm{Pa}_{\mathrm{a}} \mathrm{O}_{2} \text { : } \\
\text { arterial partial pressure of oxygen; } \mathrm{Pa}_{\mathrm{a}} \mathrm{CO}_{2} \text { : arterial partial pressure of carbon } \\
\text { dioxide; } \mathrm{DL}, \mathrm{CO} \text { : diffusing lung capacity of carbon monoxide; \% pred: \% } \\
\text { predicted; } \bar{P} \text { pa: mean pulmonary artery pressure; RAP: right atrial pressure; } \\
\text { Ppcw: pulmonary capillary wedge pressure; } \mathrm{Cl} \text { : cardiac index; } \mathrm{Sl} \text { : systolic index; } \\
\text { PVRi: pulmonary vascular resistance index; WU: Wood units; } \mathrm{SV}, \mathrm{O}_{2} \text { : mixed } \\
\text { venous oxygen saturation; } \mathrm{NO} \text { : nitric oxide; } \Delta \bar{P} \text { pa: difference in } \bar{P} \text { pa. } \\
\text { \#: radiological abnormalities on high-resolution computed tomography of the } \\
\text { chest include lymph node enlargement, centrilobular ground-glass opacities } \\
\text { and septal lines; }{ }^{\circ} \text { : defined by Golde score }>100 . \mathrm{n}=12 \text {. }\end{array}$} \\
\hline
\end{tabular}


TABLE 2 Clinical, functional and haemodynamic parameters before intiation of epoprostenol and after 3-4 months

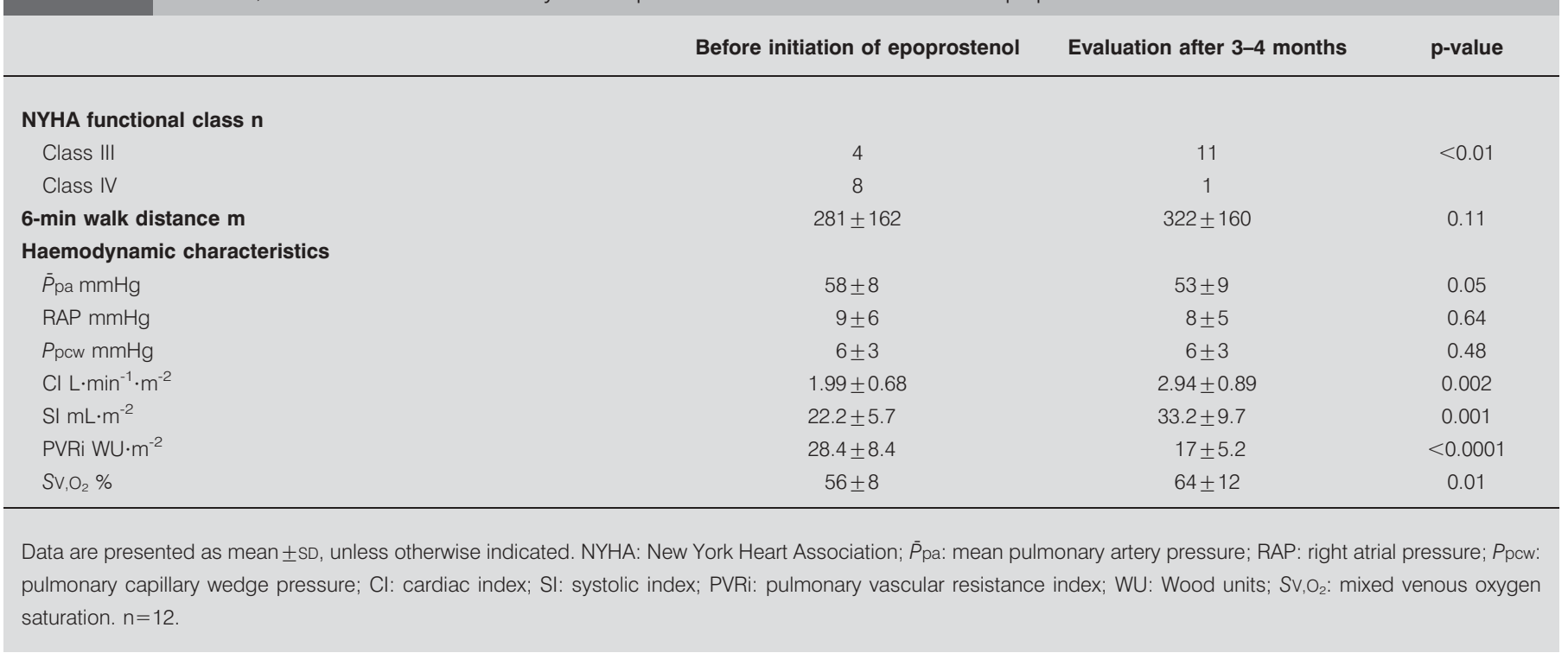

NYHA functional class III $(n=4)$ or IV $(n=8)$ with severe impaired haemodynamics (CI $1.99 \pm 0.68 \mathrm{~L} \cdot \mathrm{min}^{-1} \cdot \mathrm{m}^{-2}$ and PVRi $28.4 \pm 8.4 \mathrm{WU} \cdot \mathrm{m}^{-2}$ ). All 12 patients were treated by continuous intravenous epoprostenol within 1 yr of diagnosis (median time between diagnosis and initiation of 68 days, range 1-358) (table 3). All were listed for lung transplantation and epoprostenol was used as a bridge to transplantation. The median value of the maximal dose of epoprostenol reached in these patients was $13 \mathrm{ng} \cdot \mathrm{kg}^{-1} \cdot \mathrm{min}^{-1}$ (range $5-22$ ). This dose was obtained with a slow increase in dose titration (median time to reach maximal dose 150 days, range 5-1,065). At the time of initiation of epoprostenol, all PVOD patients received nonspecific PAH therapies including diuretics, anticoagulation and oxygen in

\begin{tabular}{|c|c|c|}
\hline TABLE 3 & \multicolumn{2}{|c|}{$\begin{array}{l}\text { Characteristics and side-effects of } 3-4 \text { months of } \\
\text { intravenous epoprostenol therapy in pulmonary } \\
\text { veno-occlusive disease }\end{array}$} \\
\hline \multicolumn{2}{|c|}{ Time between diagnosis and initiation days } & $68(1-358)$ \\
\hline \multicolumn{2}{|c|}{ Maximal dose $\mathrm{ng} \cdot \mathrm{kg}^{-1} \cdot \mathrm{min}^{-1}$} & $13(5-22)$ \\
\hline \multicolumn{2}{|c|}{ Time to reach maximal dose days } & $150(5-1065)$ \\
\hline \multicolumn{2}{|c|}{ Length of treatment with epoprostenol days } & $210(18-1106)$ \\
\hline \multicolumn{3}{|c|}{ Associated therapy at the time of initiation } \\
\hline \multicolumn{2}{|l|}{ Oxygen } & $8(66.7)$ \\
\hline \multicolumn{2}{|c|}{ Anticoagulation } & $11(91.7)$ \\
\hline \multicolumn{3}{|c|}{ Diuretics } \\
\hline \multicolumn{2}{|c|}{ Furosemide $n$} & $12(100)$ \\
\hline \multicolumn{2}{|c|}{ Daily dose mg } & $80(40-250)$ \\
\hline \multicolumn{2}{|c|}{ Spironolactone $\mathrm{n}$} & $8(66.7)$ \\
\hline \multicolumn{2}{|c|}{ Daily dose $\mathrm{mg}$} & $50(25-75)$ \\
\hline \multicolumn{2}{|c|}{ Dobutamine } & $3(25)$ \\
\hline \multicolumn{2}{|l|}{ Bosentan } & $8(66.7)$ \\
\hline \multicolumn{2}{|c|}{ Need to increase diuretics } & $4(33.3)$ \\
\hline \multicolumn{2}{|c|}{ Pulmonary oedema with epoprostenol } & $1(8.3)$ \\
\hline \multicolumn{2}{|c|}{ Need to initiate or increase oxygen therapy } & 0 \\
\hline
\end{tabular}

Data are presented as median (range) or $n(\%) . n=12$.
$100 \%, 91.7 \%$ and $66.7 \%$, respectively. All patients received diuretics: furosemide was used in all patients with additional spironolactone in eight patients $(66.7 \%)$. Due to the severity of the disease, three patients were hospitalised in the intensive care unit and received management for associated right ventricular failure with dobutamine at the time of initiation of epoprostenol.

In terms of combination therapy, eight patients $(66.7 \%)$ received the dual endothelin-receptor antagonist bosentan at the time of initiation of prostacyclin, seven patients received epoprostenol as an add-on therapy after insufficient response to first-line bosentan therapy, and epoprostenol and bosentan were initiated simultaneously in one patient.

\section{Side-effects and risk of pulmonary oedema with epoprostenol therapy in PVOD}

Common side-effects were observed in all patients including one or more of the following events: flushing, headaches, nausea, vomiting, diarrhoea and abdominal discomfort. Neither the three patients with confirmed occult alveolar haemorrhage nor the remaining nine patients developed haemoptysis. Two episodes of central line sepsis occurred in one patient (63 and 195 days after initiation of epoprostenol) with an incidence of catheter-related infections requiring change of central line of 0.64 per 1000 catheter days. No further deterioration in gas exchange was evidenced after initiation or 3-4 months of epoprostenol therapy. Only one patient developed mild pulmonary oedema that rapidly improved with an increase in diuretic therapy. An increase in diuretics was necessary in four patients $(33.3 \%)$ because of the occurrence of lower limb oedema $(n=3)$ or an increase in radiological abnormalities $(n=1)$. Interestingly, one patient had previously developed acute pulmonary oedema 7 days after initiation of calcium channel blocker therapy indicated because of an acute NO response (table 1). However, this patient did not develop pulmonary oedema with a low dose of continuous epoprostenol infusion (epoprostenol $5 \mathrm{ng} \cdot \mathrm{kg}^{-1} \cdot \mathrm{days}^{-1}$ for 30 days). 


\section{Evolution of clinical, functional and haemodynamic parameters with epoprostenol}

Evolution of clinical, functional and haemodynamic parameters of PVOD patients between 3 and 4 months following initiation of epoprostenol therapy or at the last evaluation before transplantation or death is presented in table 2 .

\section{NYHA functional class and 6-MWD}

Prior to initiation of epoprostenol, one-third $(n=4)$ of the patients was in NYHA functional class III and two-thirds $(n=8)$ were in class IV. After 3-4 months $(n=8)$ or at the last evaluation before transplantation or death $(n=4)$, NYHA functional was improved for most of the patients $(p<0.001)$, but none of them improved to functional class I or II (fig. 1). Eleven patients were in NYHA functional class III and only one patient remained in class IV (fig. 1). Three patients still waiting for lung transplantation were evaluated between 9 and 12 months of epoprostenol therapy, and these three patients remained stable in NYHA functional class III.

6-MWD was slightly improved from $281 \pm 162(0-508)$ to $322 \pm 160(0-469)$, but the difference did not reach statistical significance $(+41 \mathrm{~m}, \mathrm{p}=0.11)$ (fig. 2$)$.

\section{Haemodynamic parameters}

At 3-4 months, an improvement of haemodynamics was observed with a significant decrease of $\bar{P}_{\mathrm{pa}}(\mathrm{p}=0.05)$, PVRi $(\mathrm{p}<0.0001)$ and a significant increase of $\mathrm{CI}(\mathrm{p}=0.002)$, systolic index $(\mathrm{p}=0.001)$ and $\mathrm{SV}_{1} \mathrm{O}_{2}(\mathrm{p}=0.01)$ (fig. 3). One patient developed reversible pulmonary oedema with epoprostenol that was managed with titration of diuretic therapy. Interestingly, this patient had an overall haemodynamic improvement (PVRi from 23.9 to $16.9 \mathrm{WU} \cdot \mathrm{m}^{-2}, \mathrm{CI}$ from 1.84 to $2.54 \mathrm{~L} \cdot \mathrm{m}^{-2}$ ). Evaluation of the three patients alive and not

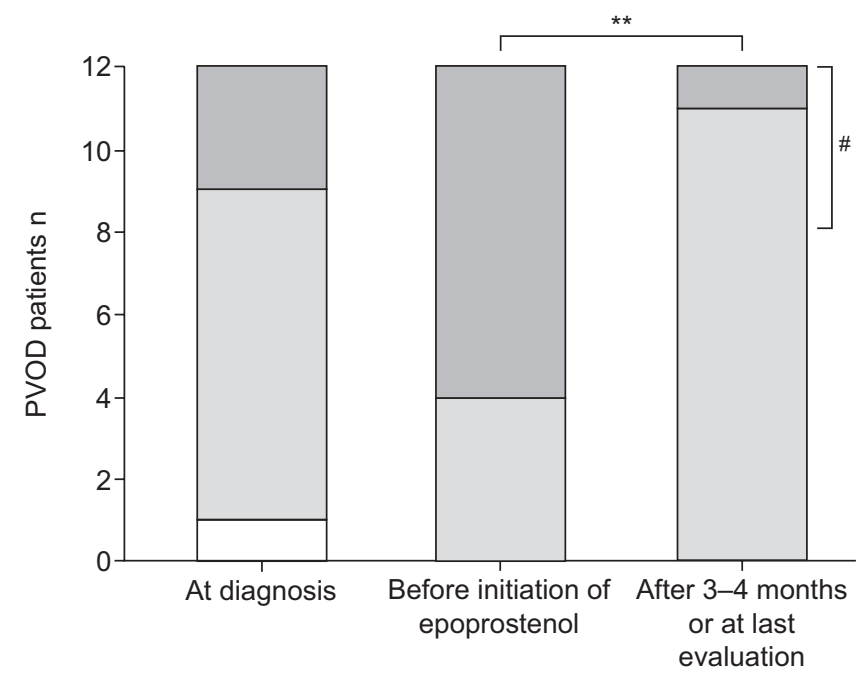

FIGURE 1. Evolution of New York Heart Association (NYHA) functional class in pulmonary veno-occlusive disease (PVOD) patients treated with epoprostenol therapy $(n=12)$. Eight patients had evaluation at 3-4 months and in four patients, NYHA functional class at the last evaluation was reported. Except for one patient who died before transplantation, all patients were in NYHA functional class III (seven patients improved from class IV to III, $p<0.01$ ), but none of them improved to functional class I or II. $\square$ : NYHA class II; $\square$ : class III; $\square$ : class IV. *: three lung transplantations and one death. ${ }^{* *}: \mathrm{p}<0.01$. transplanted 6 months after initiation of epoprostenol showed a trend to a return towards baseline with deterioration in the functional and haemodynamic improvements observed after 3-4 months (data not shown).

\section{Epoprostenol as a bridge-therapy to lung transplantation}

For all patients, listing for lung transplantation was proposed in the first year following initiation of epoprostenol (median 2.4 months, $0-12$ ). As of December 1, 2008, nine out of 12 patients had been transplanted, two had died before lung transplantation at day 145 and 201 and one was still waiting for lung transplant at day 434 (table 4). The median time between listing and lung transplantation was 49 days (1-357). In the nine transplanted PVOD patients, five had a heart-lung transplantation and four had a double lung transplantation, all of whom were alive at day 28 after surgery (table 4). Seven $(58.3 \%)$ and $11(91.7 \%)$ out of 12 patients had died or had been transplanted at 6 and 12 months following listing for lung transplantation, respectively. The time from diagnosis to death or lung transplantation is presented in figure 4 a.

In the nine transplanted patients, three died at days 52, 74 and 79 after lung transplantation, respectively. Six were still alive after lung transplantation with a median follow-up of 447 days (80-930 days). The cumulative survival of PVOD patients benefiting from a management strategy combining PAH basic therapy, intravenous epoprostenol and listing for lung transplantation is presented in figure $4 \mathrm{~b}$. Such management was associated with a 1- and 2-yr survival of $83 \%$ and $50 \%$, respectively.

\section{Statement added in proof}

The last patient on the waiting list (patient 8) was transplanted (double lung) in June 2009 after 670 days on continuous intravenous epoprostenol. Pre-transplantation clinical assessment confirmed persistent clinical and haemodynamic improvement with epoprostenol therapy. The patient was in NYHA functional class IV at the time of epoprostenol initiation

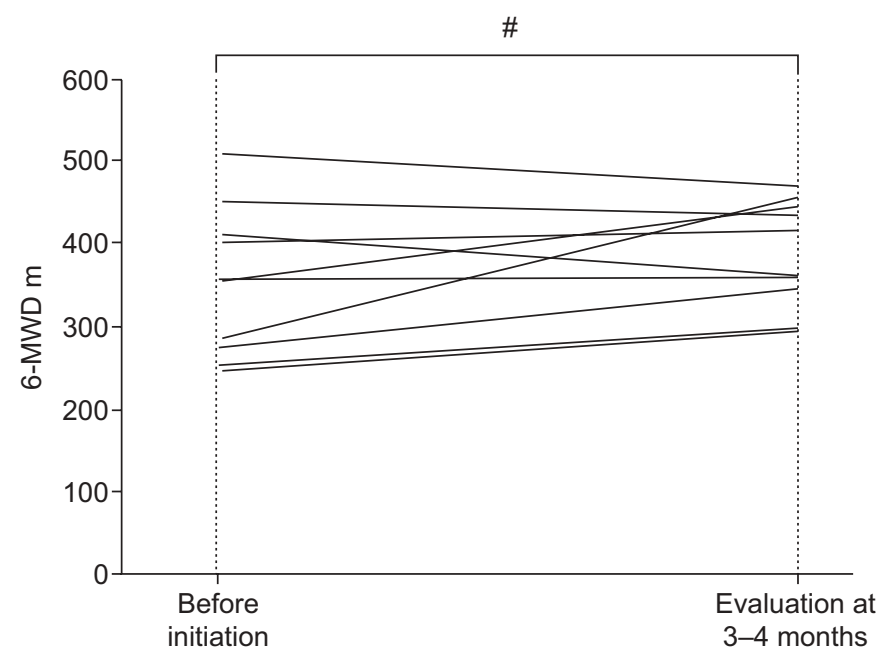

FIGURE 2. Evolution of 6-min walk distance (6-MWD) in pulmonary venoocclusive disease patients treated with epoprostenol therapy. 6-MWD was slightly improved but the difference does not reach statistical significance $(+41 \mathrm{~m})$ $\#$ : $p=0.11$ 
and in class III at the time of transplantation. Similarly, haemodynamic measurements showed an increase in CI (from 2.0 to $3.9 \mathrm{~L} \cdot \mathrm{min} \cdot \mathrm{m}^{-2}$ ) and a decrease in PVRi (from 29.7 to 18.2 WU $\cdot \mathrm{m}^{-2}$ ). No complication occurred after lung transplantation and the patient was still alive 28 days after surgery.

\section{DISCUSSION}

In this series of well-characterised PVOD patients awaiting lung transplantation, continuous intravenous epoprostenol appeared to be safe when used with a slow increase in dosage and with high-dose diuretics, and may improve functional and haemodynamic status at 3-4 months. Even if no long-term benefit was noted, epoprostenol may be considered as a potential bridge-therapy to lung transplantation in these severe patients.

First, we confirmed findings from the previous series where PVOD patients were characterised by low $D \mathrm{~L}, \mathrm{CO}$, radiological abnormalities, possible occult alveolar haemorrhage and a frequent association with tobacco exposure $[4,6,11,12]$ Interestingly, radiological abnormalities including centrilobular ground-glass opacities, septal lines and lymph node

a)

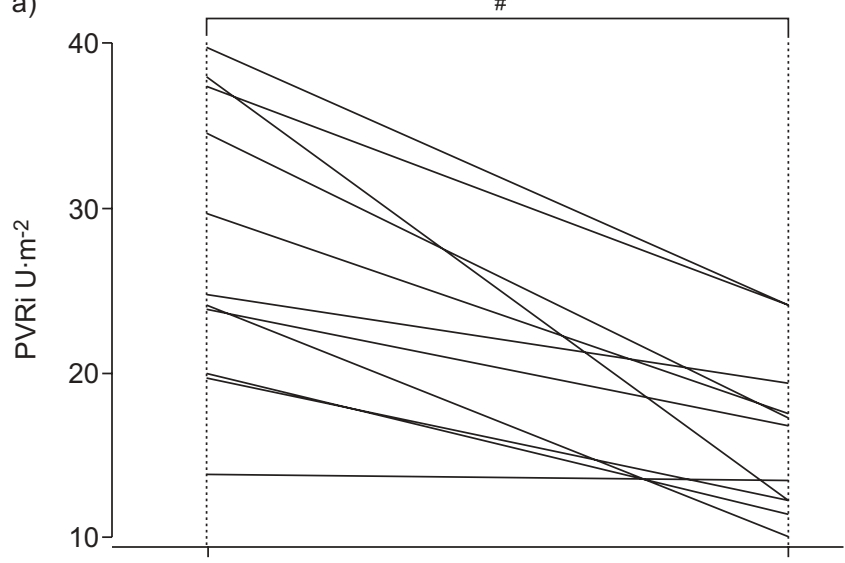

c)

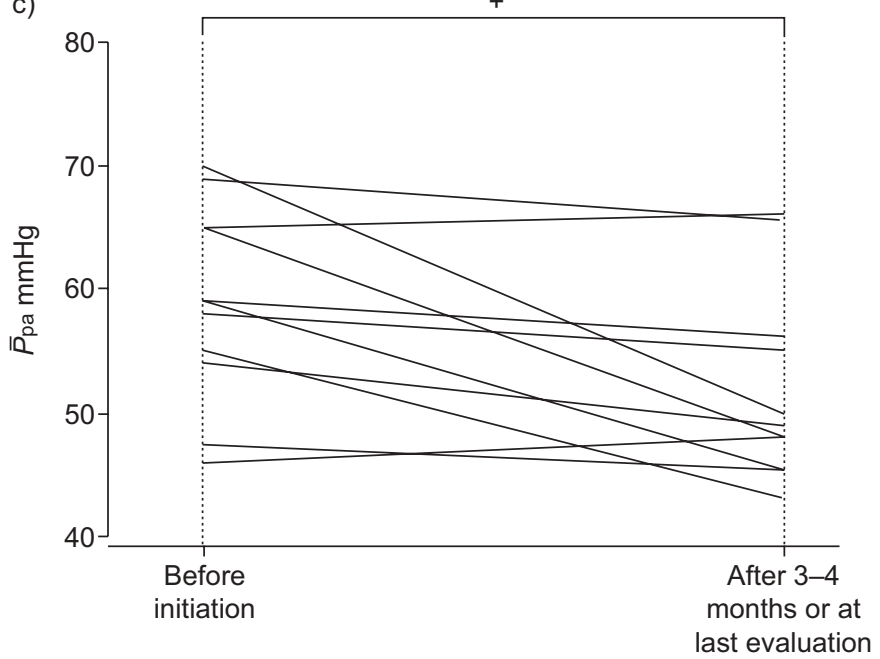

enlargement, were present in all these PVOD patients with severe disease, highlighting the sensitivity of these radiological characteristics to screen for PVOD patients $[4,6,11,12]$. As previously reported by RABILLER et al. [12] in a different series of patients, seven out of nine of our patients had a Golde score $>20$, including two with a Golde score $>100$. This series confirmed that some PVOD patients may have an acute vasodilator response [24] and even an incomplete response to acute NO testing seems to be common. Interestingly, acute responders from the present series and our previous series [6] had a similar evolution marked by severe pulmonary oedema occurring a few days after initiation of calcium channel blockers, further contraindicating their use in PVOD patients even when an acute NO response is present.

After 3-4 months of epoprostenol treatment, we observed evidence of haemodynamic improvement with a significant decrease of PVRi $(-38 \%)$ and a significant effect on systolic function with an increase in CI $(+48 \%)$ and systolic index $(+45 \%)$. As observed in idiopathic PAH, epoprostenol had a predominant effect on cardiac function and pulmonary vascular resistance, but a mild but significant decrease of $\bar{P}_{\mathrm{pa}}$

b)

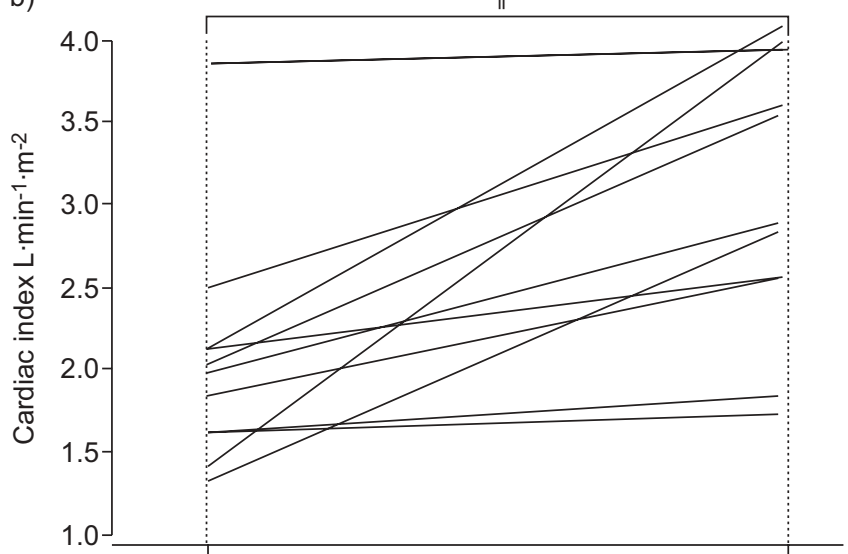

d)

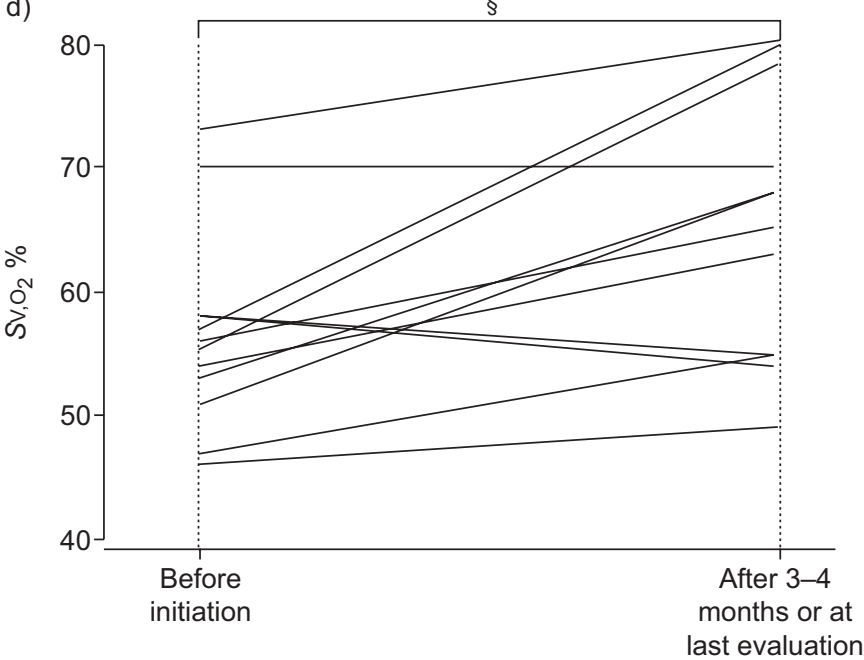

FIGURE 3. Evolution of haemodynamic parameters in pulmonary veno-occlusive disease patients treated with epoprostenol. After 3-4 months of epoprostenol therapy, an improvement of haemodynamics was observed with a significant decrease of a) indexed pulmonary vascular resistance (PVRi), c) mean pulmonary artery pressure ( $\bar{P}_{\text {pa) }}$ and a significant increase of $b$ ) cardiac index and d) mixed venous oxygen saturation $\left(S \mathrm{~V}, \mathrm{O}_{2}\right){ }^{\#}: p<0.0001 ;{ }^{\bullet}: 0.002 ;{ }^{+}: p=0.05 ;{ }^{\S}: p=0.01$ 


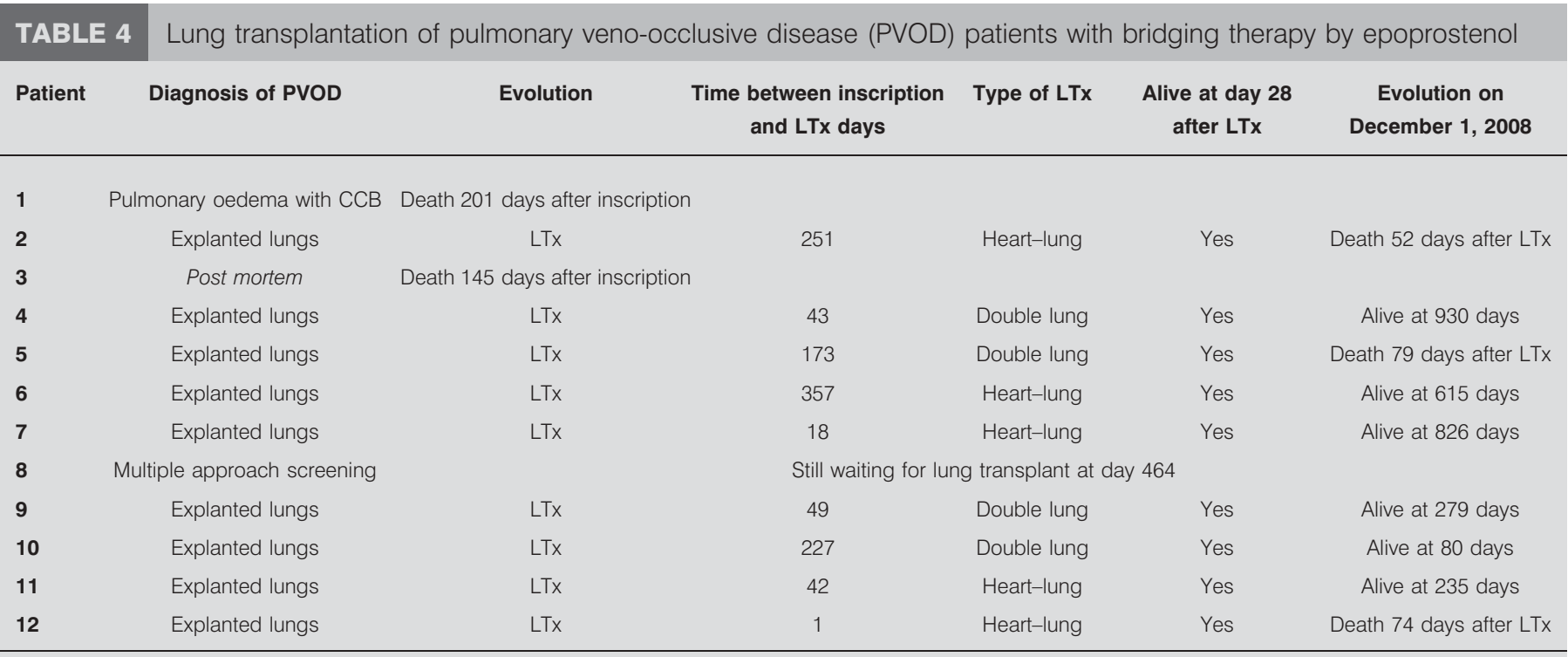

LTx: lung transplantation; CCB: calcium channel blockers. $n=12$.
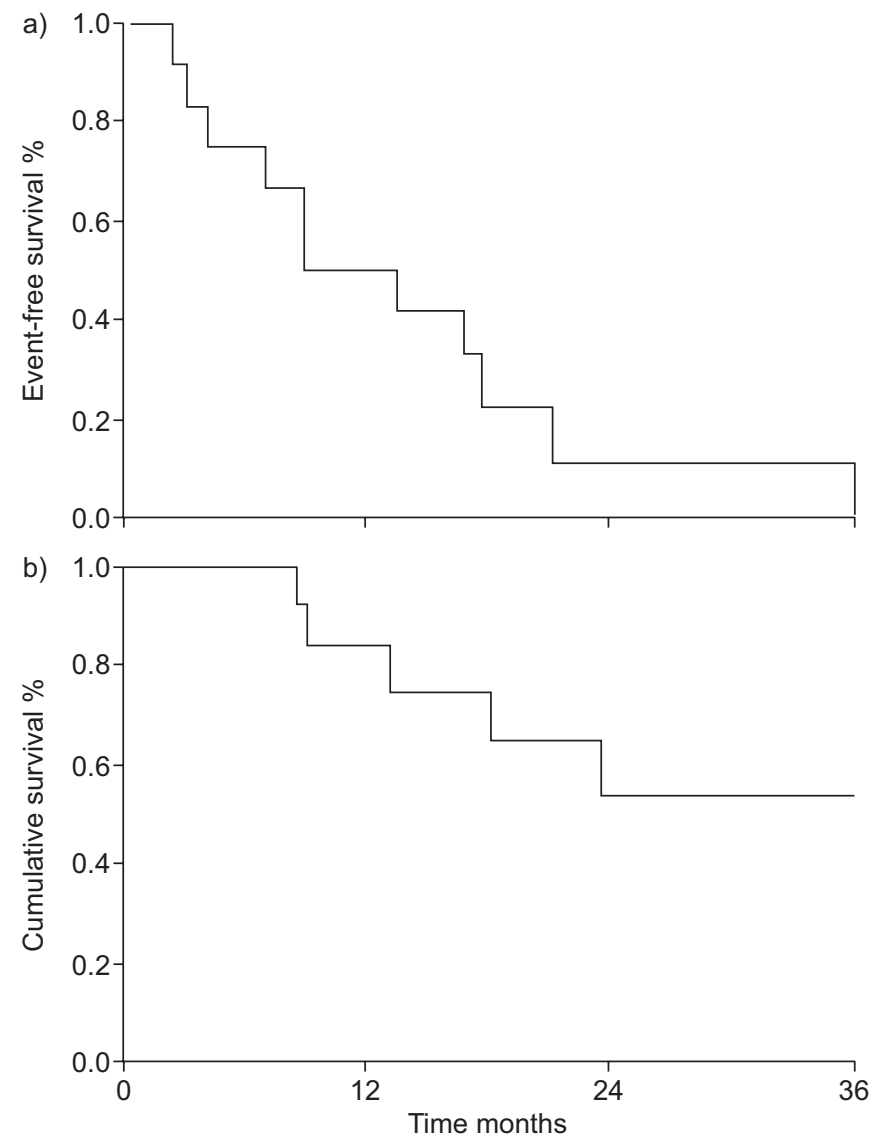

FIGURE 4. a) Time from diagnosis to death or lung transplantation. The vast majority of pulmonary veno-occlusive disease (PVOD) patients either were transplanted or died within 24 months following diagnosis of PVOD. b) Survival of PVOD patients benefiting from a management strategy combining pulmonary arterial hypertension basic therapy, continuous intravenous epoprostenol and listing for lung transplantation. was also seen. We observed a nonsignificant increase in 6MWD (+41 m, p=0.11) with a level of improvement lower than previously described in large cohorts of idiopathic $\mathrm{PAH}$ patients treated with intravenous epoprostenol in our centre (+125 $\mathrm{m}$ at 3 months) [18]. One could suggest that the response observed at 3-4 months may be due to a selection bias with inclusion of only the survivors who can be listed for lung transplantation. However, this study included all PVOD patients who received epoprostenol and were listed for lung transplantation during the study period. During the same period, only two PVOD patients received epoprostenol without being listed for lung transplantation because of contraindications. In these two PVOD patients, functional and haemodynamic improvement was broadly similar to PVOD patients listed for lung transplantation (patient 1: PVRi -24\%, 6MWD +105 m; patient 2: PVRi -27\%, 6-MWD +50 m). We can therefore conclude that the improvement observed was not due to a selection bias of survivors. Despite substantial haemodynamic improvements, the clinical response was less impressive, with no patients improving to NYHA functional class I or II, a clinical status considered as an accurate prognostic factor in idiopathic PAH patients treated by epoprostenol [18]. Even though few data on long-term response were available, no further clinical and haemodynamic improvement were obtained after 6 months, also differing from reports in idiopathic PAH [15, 16, 18].

In canine models, it has been suggested that epoprostenol may have pulmonary venodilatory properties, however little is known in humans and particularly in PVOD patients [28, 29]. Other agents, such as sildenafil, also have venodilating properties, and there are cases of clinical improvement on sildenafil monotherapy in PVOD patients $[30,31]$ or in combination with high-dose epoprostenol in one case [32]. However, pulmonary oedema may also occur in sildenafiltreated PVOD [33]. In the present PVOD study, the doses of continuous intravenous epoprostenol administered may 
appear to be relatively low. However, the doses after 3 months are in fact similar to those reported by SITBON et al. [18] 3 months after initiation of epoprostenol in idiopathic PAH $\left(14 \pm 4 \mathrm{ng} \cdot \mathrm{kg}^{-1} \cdot \mathrm{min}^{-1}\right.$, range $\left.7-34\right)$. Our study suggests that even a low dose of epoprostenol may improve haemodynamics in PVOD at 3 months. The absence of further improvement observed after 6 months may be due to tachyphylaxis, classically observed with intravenous epoprostenol use. In our experience, however, a further increase of the epoprostenol dose in PVOD patients who experienced a clinical deterioration was not followed by clinical improvement. Interestingly, more than half of the patients reported in this study received epoprostenol in combination with the dual endothelin antagonist bosentan without evidence of pulmonary oedema, indicating that awareness and drug titration are key elements to prevent this life-threatening complication of PVOD.

A very low incidence of pulmonary oedema was observed (only one mild reversible case was reported) compared with the data published in our previous series in which nearly half of the patients treated with epoprostenol developed pulmonary oedema [6]. This difference may be explained by the different periods of these two series, the second one being performed at a time with improved awareness of PVOD. The first series [6] was performed at a time when noninvasive screening for PVOD was not systematically used and for most patients, PVOD was not diagnosed until the occurrence of pulmonary oedema or histological analysis after lung transplantation or post-mortem examination of the lungs. At that time, epoprostenol was used without specific caution, using the same protocol as for idiopathic PAH patients. This second series of PVOD patients used a noninvasive approach to screen for highly probable PVOD in whom epoprostenol was initiated. In this series, the time to reach the dose of $10 \mathrm{ng} \cdot \mathrm{kg}^{-1} \cdot \mathrm{min}^{-1}$ of epoprostenol was 10-15 days and initiation of epoprostenol was associated with high-dose diuretics. The rate of epoprostenol up-titration was slower than in idiopathic PAH (5 days) and than in our previous series of PVOD patients [6]. Interestingly, five out of 11 PVOD patients developed pulmonary oedema with epoprostenol (median dose $9 \mathrm{ng} \cdot \mathrm{kg}^{-1} \cdot \mathrm{min}^{-1}$ ) in our previous series [6] as compared with one out of 12 in this current cohort despite a higher median dose $\left(13 \mathrm{ng} \cdot \mathrm{kg}^{-1} \cdot \mathrm{min}^{-1}\right)$. These data support the hypothesis that the method of screening of high-risk patients together with the use of specific precautions, such as a slow rate of up-titration and the use of high-dose diuretics, may limit the risk of pulmonary oedema. Interestingly, no significant deterioration of hypoxaemia was observed in PVOD patients after 34 months of intravenous epoprostenol therapy. Lastly, the incidence of catheter-related infection in PVOD patients was similar to the incidence previously described in $\mathrm{PAH}$ patients receiving epoprostenol [34, 35], suggesting that this patient population was not more prone to developing sepsis on intravenous epoprostenol.

Since clinical and haemodynamic improvement in PVOD patients occurs without commonly causing pulmonary oedema, cautious use of continuous intravenous epoprostenol might be helpful in the management of these patients as a bridge to lung transplantation. In this series, 11 out of 12 the patients either died or were transplanted within 12 months following listing for lung transplantation. Only two patients died while waiting for lung transplantation and nine were transplanted with a median time between listing and lung transplantation of $<2$ months. This relatively short waiting time before lung transplantation is mainly explained by the recent availability in France of urgent priority lung and heartlung transplantation, which certainly lead to earlier transplantation. Three patients died in the first 3 months after transplantation and the overall survival appears to be worse than reported in the United Network for Organ Sharing (UNOS) registry. This may be explained at least in part by the severity of these patients who were listed for urgent lung transplantation because of haemodynamic instability. However, we cannot statistically compare these results with overall survival statistics in lung transplantation due to the small number of patients in this series. Short- and long-term survival after urgent transplantation in PVOD patients should be studied prospectively in future studies. We previously demonstrated that a multiple noninvasive approach including HRCT of the chest, pulmonary function tests $\left(\mathrm{DL}, \mathrm{CO}, \mathrm{Pa}_{\mathrm{a}} \mathrm{O}_{2}\right.$ at rest, low $\mathrm{Sp}_{\mathrm{p}} \mathrm{O}_{2}$ during the 6-min walk test) and bronchoalveolar lavage if possible, allowed the screening of highly probable PVOD patients [6] and the proposition of a cautious use of intravenous epoprostenol. In our centre, PVOD patients screened by a noninvasive approach received PAH basic therapy, continuous intravenous epoprostenol and priority lung transplantation if eligible. This strategy of "best standard of care" allowed a survival of severe PVOD patients of $83 \%$ at $1 \mathrm{yr}$ and $50 \%$ at $2 \mathrm{yrs}$, which seemed to be higher than previously suggested in PVOD patients [4-7].

Furthermore, no specific complication was observed in these patients either during or after lung transplantation, and all the transplanted patients were alive 28 days after surgery. However, we have previously demonstrated that even if baseline haemodynamic, NYHA and 6-MWD parameters are similar to those observed in a series of PAH patients, PVOD patients have a worse outcome if not transplanted [4-6]. Unlike idiopathic PAH, in which epoprostenol may lead to sustained improvements in haemodynamics and survival for prolonged periods, epoprostenol was not a suitable alternative to transplantation in PVOD patients [36]. Due to constant deterioration and poor prognosis associated with PVOD, waiting for deterioration may be devastating for these patients and the initiation of continuous intravenous epoprostenol should not delay lung transplantation [10]. In our experience, when eligible, the patients with either confirmed or a very highly probable diagnosis of PVOD should be listed for urgent lung transplantation concomitantly to the initiation of continuous intravenous epoprostenol. Our study suggests the potential efficacy and the safety of this strategy for PVOD patients.

In conclusion, we have demonstrated that continuous intravenous epoprostenol may be efficient and safe in PVOD patients when used with specific precautions, including the use of highdose diuretics and a slowly titrated increase in dose. However, although epoprostenol leads to an initial improvement, this is not sustained after 6 months, suggesting that it is most suited as a bridging therapy before lung transplantation in patients with PVOD.

\section{SUPPORT STATEMENT}

This study has been supported in part by grants from Ministère de l'Enseignement Supérieur et de la Recherche (GIS-HTAP), Chancellerie 
des Universités, Legs Poix, France, and Université Paris-Sud, Paris, France. L.C. Price is the holder of a European Respiratory Society Long-term Research Fellowship no. 139.

\section{STATEMENT OF INTEREST}

A statement of interest for O. Sitbon and M. Humbert can be found at www.erj.ersjournals.com/misc/statements.dtl

\section{REFERENCES}

1 Rubin L. Primary pulmonary hypertension. N Engl J Med 1997; 336: 111-117.

2 Simonneau G, Galie N, Rubin LJ, et al. Clinical classification of pulmonary hypertension. J Am Coll Cardiol 2004; 43: Suppl. 12, 5S-12S.

3 Humbert M, Sitbon O, Simonneau G. Treatment of pulmonary arterial hypertension. $N$ Engl J Med 2004; 351: 1425-1436.

4 Holcomb BW Jr, Loyd JE, Ely EW, et al. Pulmonary veno-occlusive disease: a case series and new observations. Chest 2000; 118: 1671-1679.

5 Mandel J, Mark EJ, Hales CA. Pulmonary veno-occlusive disease. Am J Respir Crit Care Med 2000; 162: 1964-1973.

6 Montani D, Achouh L, Dorfmuller P, et al. Pulmonary venoocclusive disease: Clinical, functional, radiologic, hemodynamic characteristics and outcome of 24 cases confirmed by histology. Medicine (Baltimore) 2008; 87: 220-233.

7 Montani D, Price LC, Dorfmuller P, et al. Pulmonary venoocclusive disease. Eur Respir J 2009; 33: 189-200.

8 Pietra GG, Capron F, Stewart S, et al. Pathologic assessment of vasculopathies in pulmonary hypertension. J Am Coll Cardiol 2004; 43: Suppl. 12, 25S-32S.

9 Lantuejoul S, Sheppard MN, Corrin B, et al. Pulmonary venoocclusive disease and pulmonary capillary hemangiomatosis: a clinicopathologic study of 35 cases. Am J Surg Pathol 2006; 30: 850-857.

10 National Pulmonary Hypertension Centres of the UK, IrelandConsensus statement on the management of pulmonary hypertension in clinical practice in the UK and Ireland. Thorax 2008; 63: Suppl. 2, ii1-ii41.

11 Resten A, Maitre S, Humbert M, et al. Pulmonary hypertension: CT of the chest in pulmonary venoocclusive disease. AJR Am J Roentgenol 2004; 183: 65-70.

12 Rabiller A, Jais X, Hamid A, et al. Occult alveolar haemorrhage in pulmonary veno-occlusive disease. Eur Respir J 2006; 27: 108-113.

13 Gomberg-Maitland M, Olschewski H. Prostacyclin therapies for the treatment of pulmonary arterial hypertension. Eur Respir J 2008; 31: 891-901.

14 Rubin LJ, Groves BM, Reeves JT, et al. Prostacyclin-induced acute pulmonary vasodilation in primary pulmonary hypertension. Circulation 1982; 66: 334-338.

15 Barst RJ, Rubin LJ, Long WA, et al. A comparison of continuous intravenous epoprostenol (prostacyclin) with conventional therapy for primary pulmonary hypertension. The Primary Pulmonary Hypertension Study Group. N Engl J Med 1996; 334: 296-302.

16 McLaughlin VV, Genthner DE, Panella MM, et al. Reduction in pulmonary vascular resistance with long-term epoprostenol (prostacyclin) therapy in primary pulmonary hypertension. $N$ Engl J Med 1998; 338: 273-277.

17 Shapiro SM, Oudiz RJ, Cao T, et al. Primary pulmonary hypertension: improved long-term effects and survival with continuous intravenous epoprostenol infusion. J Am Coll Cardiol 1997; 30: 343-349.

18 Sitbon $\mathrm{O}$, Humbert $\mathrm{M}$, Nunes $\mathrm{H}$, et al. Long-term intravenous epoprostenol infusion in primary pulmonary hypertension: prognostic factors and survival. J Am Coll Cardiol 2002; 40: 780-788.

19 Cabrol S, Souza R, Jais X, et al. Intravenous epoprostenol in inoperable chronic thromboembolic pulmonary hypertension. J Heart Lung Transplant 2007; 26: 357-362.

20 Okumura H, Nagaya N, Kyotani S, et al. Effects of continuous IV prostacyclin in a patient with pulmonary veno-occlusive disease. Chest 2002; 122: 1096-1098.

21 Humbert M, Sitbon O, Chaouat A, et al. Pulmonary arterial hypertension in France: results from a national registry. Am J Respir Crit Care Med 2006; 173: 1023-1030.

22 Chazova I, Robbins I, Loyd J, et al. Venous and arterial changes in pulmonary veno-occlusive disease, mitral stenosis and fibrosing mediastinitis. Eur Respir J 2000; 15: 116-122.

23 Dorfmuller P, Humbert M, Perros F, et al. Fibrous remodeling of the pulmonary venous system in pulmonary arterial hypertension associated with connective tissue diseases. Hum Pathol 2007; 38: 893-902.

24 Sitbon O, Humbert M, Jais X, et al. Long-term response to calcium channel blockers in idiopathic pulmonary arterial hypertension. Circulation 2005; 111: 3105-3111.

25 ATS Committee on Proficiency Standards for Clinical Pulmonary Function LaboratoriesATS statement: guidelines for the six-minute walk test. Am J Respir Crit Care Med 2002; 166: 111-117.

26 Provencher $\mathrm{S}$, Chemla $\mathrm{D}$, Herve $\mathrm{P}$, et al. Heart rate responses during the 6-minute walk test in pulmonary arterial hypertension. Eur Respir J 2006; 27: 114-120.

27 Paciocco G, Martinez FJ, Bossone E, et al. Oxygen desaturation on the six-minute walk test and mortality in untreated primary pulmonary hypertension. Eur Respir J 2001; 17: 647-652.

28 Davis LL, deBoisblanc BP, Glynn CE, et al. Effect of prostacyclin on microvascular pressures in a patient with pulmonary venoocclusive disease. Chest 1995; 108: 1754-1756.

29 Greenberg S. Effect of prostacyclin and 9a,11a-epoxymethanoprostaglandin $\mathrm{H}_{2}$ on calcium and magnesium fluxes and tension development in canine intralobar pulmonary arteries and veins. J Pharmacol Exp Ther 1981; 219: 326-337.

30 Barreto AC, Franchi SM, Castro CR, et al. One-year follow-up of the effects of sildenafil on pulmonary arterial hypertension and veno-occlusive disease. Braz J Med Biol Res 2005; 38: 185-195.

31 Creagh-Brown BC, Nicholson AG, Showkathali R, et al. Pulmonary veno-occlusive disease presenting with recurrent pulmonary oedema and the use of nitric oxide to predict response to sildenafil. Thorax 2008; 63: 933-934.

32 Kuroda T, Hirota H, Masaki M, et al. Sildenafil as adjunct therapy to high-dose epoprostenol in a patient with pulmonary venoocclusive disease. Heart Lung Circ 2006; 15: 139-142.

33 Montani D, Jaïs X, Dorfmuller P, et al. Goal-oriented therapy in pulmonary veno-occlusive disease: a word of caution. Eur Respir $J$ 2009; 34: 1204-1206.

34 Oudiz RJ, Widlitz A, Beckmann XJ, et al. Micrococcus-associated central venous catheter infection in patients with pulmonary arterial hypertension. Chest 2004; 126: 90-94.

35 Sitbon O, Humbert M, Simonneau G. Primary pulmonary hypertension: current therapy. Prog Cardiovasc Dis 2002; 45: 115-128.

36 Barst RJ, Rubin LJ, McGoon MD, et al. Survival in primary pulmonary hypertension with long-term continuous intravenous prostacyclin. Ann Intern Med 1994; 121: 409-415. 